\title{
Women with disabilities: some aspects of invisible lives
}

Wendi Wicks*

This paper analyzes the issue of women with disabilities. The underpinning argument is that this oppression, and how it is experienced, must be seen in the light of both ableism and sexism, since neither alone provides a sufficient explanatory basis. The way this oppression is experienced in the area of work is illustrated in relation to employment, incomes, and housework. The related areas of legislative and social policy areas are also briefly considered. Implications and directions for policy formulation are explored.

\section{Introduction}

For a number of years, the recognition has grown that certain groups experience distinctive issues and difficulties which are due to discrimination in relation to work. Among the groups whose issues have been recognized are women and people with disabilities. There is, however, minimal recognition that there are distinctive issues for women with disabilities. These issues are particularly distinctive in relation to work, although work issues are by no means the whole story. Work-related discriminations are used in this article to illustrate and explain the situation.

Issues for women with disabilities are, if they are considered at all, subsumed as part of issues for women, or as part of the issues for people with disabilities. The argument that underpins this article is that such an approach is insufficient: that factors of both ableism (discrimination on the basis of disability) and sexism (discrimination on the basis of sex) are central to the issue, and an understanding based on either, alone or principally, is insufficient. It is only when both are given consideration that discrimination can be fully addressed, and an appropriate conceptual framework for policy formulation be formed.

These underpinnings are discussed in the following section. Then, in the light of this argument, the article examines issues of work for women with disabilities in Aotearoa. This examination covers education, unemployment and employment, incomes and housework. Some comparisons with overseas data attest to the international nature of the issues. A concluding section discusses the implications of this information for policy provision, and offers some guidelines for future policy formulation.

The article neither aims to present a perspective of Maori women with disabilities nor does it attempt any analysis of their situation. 1 What is noted is that the oppression of racism will be present in addition to ableism and sexism, and will most likely compound the oppression.

With regard to language, 2 stances have been adopted. First, the phrase women with disabilities is used. Although this, at times, results in clumsy phraseology, I would far rather tread on syntax than on the principle of requiring respect for the inherent humanity

* State Services Commission.

1 That is no more appropriate for a Pakeha woman with disabilities, than it would be for a male with disabilities to describe the experience of women with disabilities. 
of women with disabilities as recognized in word use. Second, the phrase they/we is at times used in relation to women with disabilities. My identification as a woman with a disability is clear, and it would be contradictory were I not to own this identity. They/we recognizes the ever-present nature of our oppression, and how close discrimination is to all of our lives.

In examining issues for women with disabilities, it becomes readily apparent that there is little data to aid in illustrating the points made. In quantitative surveys, the measuring categories chosen are most likely to be women, or people with disabilities. Only occasionally does the breakdown of data include the category of women with disabilities. However, the data that is available is internally consistent and in broad agreement with the situation experienced and articulated by women with disabilities. What this lack of data raises is the question of why there is such a lack. This very lack is one of the reasons that such an article is necessary, and speaks loudly about the perceived importance of the issue.

There is one more aspect to the issue of data: definitions of disability. Of the data which is available, most relates to the limiting "medical model" definitions of disability that are individualistically oriented, and talk in terms of functional limitations. (The deficiencies of the medical model are delineated in Sullivan's article in this symposium). But data based around these definitions are all that is available. It is interesting to speculate on the discriminations that medical model-based data reveals. If discrimination on such a scale is illustrated by data with a restrictive base, what might be shown if social definitions of disability, based on societal disablement, were used as a base?

\section{Underpinnings}

It is argued here that the situation of women with disabilities can only be described and analysed in terms of an interaction of ableism and sexism: 2 discriminations in combination. A basis to this description is to understand what discrimination is and what are its consequences.

Discriminations begin with ideas which are then translated into actions. At the stage of ideas, individuals are identified as belonging to a group because they possess some real or imagined characteristic, which is then adjudged inferior. This "inferior" characteristic is frequently associated with other, undesirable characteristics. The evaluation, based on these negatively valued characteristics, is then generalized so that the whole group is judged inferior. The ideas of inferiority, formed into stereotypes, are then used as a rationale for second rate treatment/discrimination against the group. An instance is where people with disabilities are, because of some physical "deficit", adjudged as being unable to work at "100 percent". They are, in consequence, awarded lower wages, and are seen to be less employable.

Discrimination against a group can be seen in social indicators; those measures of various aspects of our social life such as housing, health, education or employment. Figures gathered in relation to, say, unemployment rates or to levels of academic qualifications at school often demonstrate differences between groups. They show the particular ways that discrimination operates on a group, and how it differs between groups.

For sex-based discrimination in relation to work, the distinctive issues for women include the devaluing of skills gained through unpaid work, particularly housework, and "protective" legislation. People with disabilities face some different issues: access (to buildings, to technology, to communication), job design, human rights legislation and occupational gradings. There are issues common to both disabled and non-disabled women. These include occupational segregation, lower pay rates, high unemployment rates, difficulties in obtaining full time employment, and an antithetical organizational culture. Negative attitudes and stereotypes are almost a sine qua non for discrimination. 
The similarities have distracted from the fact that the issues for women with disabilities are distinct. Most often women with disabilities are said to face discrimination because they/we are women, or because they/we have disabilities. That is, they/we face principally ableism or principally sexism. This is reflected in literature. In feminist writings, Grimsdell (1985) gives a particularly clear example of the "it's because they're women" school, while disability writers, even such as Oliver (1990) talk about the impact of gender on disability.

Such a tendency towards dichotomous thought about the way different discriminations combine is not new. Cass's (1978) delineation of the way sex and class interact, with her conclusion that sex is a minor adjunct to class discrimination, is a clear example, representing the mainstream of thought to date. The problem that such descriptions raise is that they give an incomplete understanding to the situation, with a consequence that policy formulation is inappropriate to the parameters of the situation. Some beginnings of an inclusive formulation are visible. Lawrie's (1987) writings discuss the impossibility of a central, all-inclusive identity, and the way a variety of identities interact. This is very relevant to the central argument here: that until there is proper recognition of the situation for women with disabilities, and of the major factors in the situation, ableism and sexism, proper action towards removal of the discriminatory barriers (including through policy provision) is uncertain.

Ableism and sexism interact for women with disabilities in a variety of ways. The compound is one that denies a simplified rank-ordering of ableism and sexism into which is seen to be more important. As the following sections make clear, one aspect of work discrimination may show a predominance of sexism, while others show more influences of both ableism and sexism. No particular pattern is evident.

An example will illustrate this combination of both ableism and sexism. In a 1982 survey for the Wellington Hospital Board, the average unemployment rate for people with disabilities was 33.5 percent. (At the time the rate for the general population was 2 percent and for women 2.8 percent.) But the rate for women with disabilities was significantly higher than the rate for people with disabilities - it was 44.7 percent (Jack et al., 1982). Clearly here, both influences are significant.

\section{Education}

Education is usually a strong determinant of work opportunities. There is some evidence that educational qualifications do not greatly enhance employment prospects for women with disabilities (Fine and Asch, 1988). However, opinion that educational opportunities are central in making a link to work for people with disabilities (Johns, 1991 ; OECD , 1990) is much stronger, and is consonant with the lived experience of women with disabilities in Aotearoa.

From the beginning, "opportunities" are limited for students with disabilities. From early childhood education, through to the unwelcoming environment provided by most universities and to continuing education, people with disabilities are poorly served. The "recognition" that a child is difficult to educate, or even ineducable, is likely to be made on the basis of disability. It has consequences of lowered teacher expectation and diminished contact time. Both of these factors make a lesser performance more likely, and that in turn reinforces those negative expectations.

The education system is not set up to assist the needs of girls either. Research has, on a number of occasions, shown how teacher interaction is, for them, very much diminished. This means less of an opportunity to "talk knowledge into place". Sexist teaching practices are said to have anti-learning effects (Alton-Lee, 1990). Further negative factors include social learning of sex-appropriate study options, and diminished expectations for further learning (Abigail, 1983). 
Neale's (1984) study of subject options and levels of education illustrates the operation of educational discrimination. Students with disabilities were much more likely to leave school early than students without disabilities. 25 percent of them intended to leave school at 15 , while only 18 percent of students without disabilities intended this. "No more progress" was the second most common reason for the students with disabilities' leaving; 12.6 percent of them left for this reason while only 2.6 percent of the students without disabilities saw that as the reason (Neale, 1984). This is a clear difference in expectations of achievement of the 2 groups.

Lowered expectations for students with disabilities were shown in other ways. While 6.3 percent of the parents of students with disabilities expected that their child would become unemployed, only 1.6 percent of the parents of students without disabilities had similar expectations. The important thing is the substantially lowered expectations for students with disabilities. In addition, only 2.9 percent of the parents of disabled students saw any possibility for further education, in comparison with 54.8 percent of the parents of non-disabled students - a massive difference in expectations (Neale, 1984).

For female students with disabilities, the lack of belief in their abilities was even more pronounced. They were seen as best suited to "soft option" areas of study which would even more circumscribe their further educational and career planning opportunities. For them, suitable employment was most likely to be a clerical or sales job. Male students with disabilities were seen as suited to a much wider range of jobs. Here the "expectations" of gendered learning, and the impact of sexism is evident (Neale, 1984).

What emerges from this work is how disability is much more a factor than is sex in discrimination against female students with disabilities. This is echoed in the belief of the parents of students with disabilities. Most ( 70 percent) believed that disability was an overriding factor. But the study shows that a diminished belief in the capacities of girls to achieve educationally is also operational.

\section{Employment}

The expectation that students with disabilities will be unemployed is a very accurate picture of reality. To begin with, people with disabilities are a low proportion of the workforce. In 1981, the rate was 44 percent compared with the rate for the general population of 83 percent, and in 1986 it was 41 percent (BERL, 1986). Data from the US (Fine and Asch, 1990) is more specific. The participation rate for women with disabilities was 24 percent, while for women without disabilities it was 64 percent. Australian data (Ronald, 1990) shows a similar picture: for women the participation rate was 24 percent, while the overall rate was 72 percent.

Of those in the workforce, large numbers are unemployed. In 1981, Jack et al. estimated the unemployment rate for people with disabilities at 38.6 percent. At the time, the general unemployment rate was 2 percent, and the rate for women was 2.7 percent. In 1981, an unpublished International Year Of Disabled Persons study done in Auckland found the rate to be 48 percent. And a recent, unpublished Vocational Opportunities Support Programme study found the rate to be 41 percent, though methodological difficulties with this suggest that the figure may be something of an underestimate.

There are other data that relate less directly to unemployment, but still fit the trends noted. In a 1982 survey, Shipley (1982) noted that 1 person in 3 who was unemployed reported a disability. And although for both men and women the relationship between unemployment and disability was strong, for women, she found the relationship was very much more pronounced.

What is especially interesting about Jack's (1982) survey figures is that they provide a sex-disability breakdown that is uncommon in this country. For men with disabilities, the unemployment rate was 22.4 percent, half that of the 44.7 percent rate for women 
with disabilities. This is comparable with overseas figures, even possibly conservative. Fine and Asch (1988) note that two-thirds of women with disabilities in the American labour force are unemployed.

The difference in employment for men and women with disabilities seen in the scattered data fits with the experience of women with disabilities. Present estimates, which have no evidential backing, of a rate approaching 80 percent may be a little high. But it certainly is towards the top end of the unemployment scale. When general unemployment rates have increased considerably to around 10 percent, it is unlikely that the employment rate for women with disabilities will have gone down since 1982 .

In Aotearoa, women with disabilities are most likely to find employment in the public sector, if they/we find it at all. It has been, and arguably still is, the largest employing area for people with disabilities. But the obtaining of employment there is likely to have been at considerable personal cost. They/we will have horror stories to tell about getting there. The stories will be about interview panels, stereotyped expectations, inflexible job design and performance standards, pay and promotion, workmates' attitudes, job evaluations. In short, the works. Much of the discrimination encountered can be attributed to ableism.

While these sorts of discriminations impact on all people with disabilities, it is even more intense for women with disabilities. Sexism also is apparent. Two illustrations of this are in the areas of occupational segregation and pay and promotion.

In a report on the employment of disabled people for the State Services Commission, Stone (1986) pointed to occupational segregation of women with disabilities. In her report, women with disabilities were in a total of 9 , lowly graded support occupations. Men with disabilities were in 23 diverse occupations, with a range of gradings. This finding echoes Neale's (1984) report finding, discussed earlier, of low expectations and limited occupational choices for female students with disabilities.

Low grading and a limited occupational range means low pay and a lack of promotion. The public service census on ethnicity and disability (Gray and Burns, 1989) reflects this. Of women with disabilities, 71 percent were on or below the second-lowest step of the pay scale, earning under $\$ 30,000$ per annum. Only 41 percent of the men with disabilities earned this little.

This situation changed only minimally when length of service was accounted for. Although 18 percent of both sexes had been on the job 11 to 15 years, 65 percent of the women with disabilities were still earning under $\$ 30,000$ per annum. At the top end of the scale, discrimination was also visible. 21 percent of the men with disabilities earned over $\$ 40,000$ per annum, compared with 4.5 percent of the women. Even allowing for a diminished labour force participation rate, and increased unemployment, the figures still show the presence of discrimination due to sex, more prominently than to disability, though again, both are evident.

In employment, ableism and sexism interact in a number of different ways. There is a recognizable picture though that both have considerable discriminatory impact on the lives of women with disabilities.

\section{Incomes}

In this arena, very compelling indicators attest to the effects of the double discrimination, and the great poverty it means. Jack et al.'s (1982) survey results found that 54 percent of the women with disabilities had an income under half that of the average female wage while 26 percent of the men with disabilities had an income under half of the average male wage. This is no indicator of an opulent lifestyle, and its effect on men with disabilities is in no way to be minimized. It rather serves as an accentuation of the reality of living with a disability if one is female - particularly when 
we bear in mind that the average female wage was three-quarters of the male wage - it is highly likely to be penurious.

In considering this finding, and possible reasons for it, some exploration of benefit structures, and of eligibility is illuminating and explanatory. First, larger numbers of women with disabilities are likely to be on benefits. The benefits likely to provide income are of 3 principal varieties: Unemployment Benefit (UB) Invalids Benefit (IB) and Accident Compensation (AC).

Second, more women with disabilities are likely to be eligible for/receive UB or IB. They/we are unemployed in greater numbers to begin with and a large number are not in the labour force. Shipley's work reveals large numbers of discouraged job seekers. For those not in the workforce, for whatever reason, the benefit for which they will most likely be eligible is IB. This is because the conditions that women with disabilities are most likely to have are as a result of illness, or are congenital.

When eligibility is considered, benefit level differences, and differences in criteria also become apparent. The IB or UB which are available to most women with disabilities are lower overall than AC and are means tested. AC is awarded at a percentage of the rate a person earned before injury, does not have a fixed single level, and is thus higher. Further, the rate at which it is granted is not means tested, and is independent of any partner's level of income. But even those women with disabilities who receive AC are unlikely to get it at a high rate. As mentioned, it is awarded at a rate proportional to what was previously earned. Most women with disabilities were employed at a lower wage than males with disabilities.

The restrictiveness of IB or UB is emphasized by the limit on additional income before the benefit is abated being set at a low level. The assumption of dependency built into these benefits is highly applicable to stereotypes of disability, but it is at least as much built into gender stereotypes. The differences in income levels between men and women with disabilities is embedded in the benefit structures and is seen to show, in this facet of discrimination, how powerful a force sexism can be in their/our lives. But it also warns of how short sighted it would be to discount the effects of ableism.

\section{Housework}

The role of sexism is particularly evident when housework, and the "caring for" it tends to involve, is considered. This can be seen by contrasting societal expectations for the partners of men or women with disabilities. If a woman has a disability, it is assumed that a male partner would continue to perform a job in the workplace, and that "caring for" duties would be performed by another woman - a female relative, or hired help. But when the circumstances are reversed, it is expected that a female partner will concentrate her time and energy in caring for his needs as well as performing household tasks, perhaps for the rest of the family.

Anecdotal evidence suggests that these sex-based assumptions also exist in same-sex partnerships. That is, women would be expected to care for the needs of a woman partner with a disability, but men would not be expected to care for their disabled partner. The parallels for women in caring for situations generally (Hicks, 1988) is evident.

What this means is that in a relationship with a man, women with disabilities carry most of the responsibility for household duties. Jack et al.'s $(1981,1982)$ survey found that over 80 percent of the women with disabilities took responsibility for household tasks in spite of the difficulty these presented. Women both under and over 65 shopped, cooked, did the laundry, and did the housework. Men bore primary responsibility for gardening - another testament to the division of labour along sex-role stereotyped lines.

That this pattern of responsibility is similar to that of couples without disabilities is attested to by Fletcher (1978) and Oakley (1974). And the reasons given by women with 
disabilities for doing so are also similar: the performance of the duties indicates status, feelings of failure or guilt if they are not done (Phillips 1981).

For women with disabilities there is an additional reason for a performance of housework duties even when, as Jack et al. (1982) demonstrate it may involve undue amounts of effort and/or pain. It relates to the marginal role of women with disabilities, and is the feeling that housework is unskilled work that can be done by anybody (Baxter, 1976).

Many women with disabilities are unable to be in the workforce but look for some measure of self esteem through the performance of housework. If one finds difficulty in doing something that "anybody" can do, what does that imply? To many of us, a lack of "success" in this most basic of work duties implies a lack of success with any work, even at anything related to being female. As Fine and Asch (1989) remind us, the stereotypes of women with disabilities and sex-role stereotypes are at considerable variance. Expectations of performing a "nurturing" role is at variance with the dependency stereotype of the disabled. Locked into 2 contradictory and socially constructed stereotypes, women with disabilities often find the demands of unpaid work are very high, imposing layered discriminations and extra difficulties.

\section{Implications for policy provision}

The information in the preceding sections illustrates the largely unrecognized discriminations that comprise a large part of the invisible lives of women with disabilities. The dynamic interplay of ableism and sexism in relation to work is shown.

Given the understanding implied in earlier sections that discriminations such as ableism and sexism are social constructions, it would seem sensible to address the consequences, at least in part, through social policy: laws, policies and practices. Where this has happened (for instance the equal employment opportunities provisions contained in the State Sector Act 1988) there has been some diminution of discrimination. For public policy provision to succeed, though, it should be appropriate. And in relation to that, there are 2 implications of the previous sections.

First, it can be seen that the interaction of ableism and sexism follows no single pattern. This means that policy guidelines will work poorly if they are monolithic. Rather they should be loosely structured and able to fit to the situation that exists so that policy answers to the reality.

Second, although this article has concentrated on illustrating a selection of the issues, discrimination exists in almost every other aspect of our lives. So policy guidelines need also to be broad. While it is possible that policy may well be created to fit a situation, it is necessary to form some systematic base from which a situational approach, related to work, for instance, can proceed.

In forming a base, consultation is of central importance. Without consultation, the "solutions" are likely to become unsatisfying ritual observances that serve only to perpetuate powerlessness. Public policy is not the only strategy to address issues of discrimination for women with disabilities. But in any provision to be made that speaks to our needs, policy should be an integral part: it is an appropriate means to address a problem that has its genesis in social constructions. 


\section{Policy guidelines}

The following guides are offered in relation to the formulation of policy that impacts on women with disabilities. They represent a starting formulation: further thought/discussion/amplification/input from other women with disabilities is an aim. The guidelines have been formulated at the level of overview, and do not address specific issues.

\section{(a) For all policy ask "Does it have implications for women with disabilities?"}

Although this question is especially relevant to policy related to women or to disability, many other areas are relevant too. Investigation should not be superficial.

\section{Actions}

- Become familiar with the literature/issues in this area.

- Contact women with disabilities networks/ disability consultants/relevant disability organizations with policy responsibilities.

(b) The involvement of Maori women with disabilities in both consultation and policy creation is vital.

In creation and consultation, policy formation needs to involve partnership.

\section{Actions}

- Develop and maintain contacts with appropriate groups. These may include the Maori Women's Welfare League, Iwi Authorities, Networks of Maori women with disabilities.

(c) Women with disabilities need to be involved in policy creation.

In such involvement, there should not be tokenism; full participation is required.

Such women should have adequate power to act, have adequate support, and be adequately resourced.

\section{Actions}

- Seek out suitable women from within government, private enterprise or in the community through networks or relevant disability/women's organizations.

(d) Women with disabilities must be consulted.

Consultation with women with disabilities should occur additionally to the third guideline. Consultation needs to involve a genuine openness so that firmly deciding policy beforehand, or marketing it to those consulted, does not occur. The focus and level of consultation relates to how widely the policy applies. National policies will require consultation at that level.

\section{Actions}

- Identify key women with disabilities in a community.

- Be sure to involve networks.

- If you are seeking submissions, ensure (i) an adequate timeframe; (ii) publicity in appropriate channels and (iii) that they can be made in a variety of mediums.

- Be prepared to pay for the expertise of key women and network overheads. Fragile networks should not be exploited.

(e) The ability of women with disabilities to be employed, and the equal worth of their work needs action.

That employment issues impact strongly on women with disabilities, and that dire poverty is a consequence is visible. It is further apparent that a situation where a large group of potentially creative contributors is sidelined does not constitute good human resource management.

\section{Actions}

- Become informed about the issues, through literature and network contacts. If you do not know the contacts, begin to find them.

- Consider how to attract, recruit and retain women with disabilities into your organization.

- Find out what needs to be considered from networks or consultants. 


\section{Conclusion}

The lives of women with disabilities has been, and still is, unknown to many. This invisibility, and the anonymity it implies, is encapsulated in 2 phrases: "Don't shout dear, it isn't ladylike" and "Let's not talk about it; it's unpleasant and anyway, we don't see you as disabled". Telling our reality is not wanted, and a deviation from polite societal pictures. But because it is not told, because it is not catered for, it seems not to exist. And while it is untold, the discriminations can also be seen to be something of a fiction.

Part of the invisibility is due to framing the issue in either-or terms - either ableism or sexism. This article has argued that the issue is neither alone, but both in combination. From the starting point of a discussion about the nature of discrimination, it has illustrated some ways this dynamic interaction is seen in relation to work.

A closing section offered some guidelines on policy which begin to address the discriminations that exist for women with disabilities, along with the hope that women with disabilities will help to shape them further. The creation of appropriate policy is a highly important part of the process of uncovering invisible lives. In that policy formulation, issues of work will continue to be vital for women with disabilities.

\section{References}

Abigail, J. (1983) Secondary school influences on the training and career aspirations of girls: a study in 17 Wellington schools. Wellington, Vocational Training Council.

Alton-Lee, A., Densem, P. and Nuthall, G. (1990) Imperatives of classroom research: understanding what children learn about gender and race. Dunedin, University of Otago.

Baxter, P. (1976) The meaning of disability. London, Heinemann.

BERL (1986) Estimates of the population of disabled people in New Zealand. Wellington, Accident Compensation Corporation.

Cass, B. (1978) Women's place in the class structure. In E. Wheelwright and K. Buckley (eds.) Essays in the political economy of Australian capitalism, Volume 3. Sydney, Australian and New Zealand Book Company.

Fine, M. and Asch, A. (1988) Women with disabilities. Philadelphia, Temple University Press.

Fletcher, G. (1978) Division of labour in the New Zealand nuclear family. New Zealand psychologist 7(2):33-40.

Gray, A. and Burns, J.A. (1989) A survey for people with disabilities in the Public Service. Wellington, State Services Commission.

Grimsdell, S. (1985) Women with deafness speak. Broadsheet, November:10-14.

Hicks, C. (1988) Who cares? London, Virago.

Jack, A., Dourado, S., Dowland, J. and Hyslop, R. (1981) Physical disabilities: results of a survey in the Wellington Hospital Board Area. Wellington, Department of Health (Special Report No. 59).

Jack, A., Dourado, S., Dowland, J. and Hyslop, R. (1982) Disabled women: a double disadvantage. Wellington, Department of Health (Occasional Paper No. 21).

Johns, K. (1991) Employment and training policies for people with disabilities: a literature review. Wellington, Department of Labour. 
Lawrie, A. (1987) Lesbian worlds. In S. Cox (ed.) Public and private worlds. Wellington, Allen and Unwin.

Neale, J. (1984) Where next? A survey of the parents of disabled form four students. Wellington, Further Education Group.

Oakley, A. (1974) The sociology of housework. London, Martin Robertson.

OECD (1990) Employment and training policies for people with disabilities. Paris (Report by Evaluation Panel No.12).

Oliver, M. (1990) The politics of disablement. London, Macmillan.

Phillips, J. (1981) Willing but unable. In Broadsheet July/August:29.

Ronald, C. (1990) National employment initiatives for people with disabilities. Canberra, Australian Government Publishing Service.

Shipley, S. (1982) Women, employment and unemployment. Palmerston North, Massey University.

Stone, J. (1986) Review of the employment of disabled persons in the Public Service. Wellington, State Services Commission. 